\title{
Technical Note: A Rapid Lipid Separation Method for Determining Fatty Acid Composition of Milk
}

\author{
S. Feng, A. L. Lock, ${ }^{\star}$ and P. C. Garnsworthy \\ Division of Agricultural and Environmental Sciences, School of Biosciences, \\ University of Nottingham, Sutton Bonington Campus, Loughborough LE12 5RD, UK
}

\begin{abstract}
A rapid method for milk lipid separation followed by transmethylation to produce fatty acid methyl esters from bovine milk samples is presented. Fat is separated by a nonsolvent method using centrifugation. The method was compared with the popular hexane:isopropanol solvent extraction method, and fatty acid proportions were statistically identical for both methods. In 108 replicates, variance accounted for by using the 2 methods was of a similar magnitude to variance due to repeat separations or repeat injections onto the gas chromatography column. It is concluded that the proposed method is accurate, simple, rapid, safe, economical, and especially suitable for large numbers of samples.
\end{abstract}

(Key words: milk fat, fatty acids, lipid, analytical method)

Abbreviation key: FA = fatty acids, FAME = fatty acid methyl esters.

\section{INTRODUCTION}

Extraction of milk lipid with organic solvent, followed by transesterification to form fatty acid methyl esters (FAME) and subsequent GLC, represents the classical method for milk fatty acid (FA) analysis. Although protocols for extraction and analysis are well established, the methods are time-consuming, laborious, costly, and impractical for processing large numbers of samples.

The solvent method of Hara and Radin (1978), using a mixture of hexane and isopropanol, is popular for milk lipid extraction prior to transesterification and analysis of FA. This multistep method has been used in our laboratory for many years for analysis of FA, including conjugated linoleic acids and transoctade-

Received June 30, 2004.

Accepted August 2, 2004

Corresponding author: P. C. Garnsworthy; e-mail: Phil. Garnsworthy@nottingham.ac.uk.

*Current address: Department of Animal Science, Cornell University, Ithaca, NY 14853. cenoic acids, in bovine milk samples (e.g., Lock and Garnsworthy, 2002, 2003). Although it is suitable for small numbers of samples, time and equipment limit throughput to approximately 40 samples per day. For this reason, and because we had thousands of milk samples to analyze, we developed a centrifugation procedure for milk lipid separation. Centrifugation has been used successfully by previous workers, e.g., Sukhija and Palmquist (1988), but usually as a one-step method that combines separation and methylation, with potential loss of volatile FA even when sealed tubes are used (Jensen, 1992). In the proposed method we used centrifugation for lipid separation, followed by conventional transesterification, with a reference standard to correct for losses of volatile FA.

The objective of the study reported here was to validate this new method, using the Hara and Radin (1978) method as a reference. At the same time, we quantified sources of variation in milk FA determination so that decisions could be made about levels of replication required for accurate results.

\section{MATERIALS AND METHODS}

Milk samples (at least $100 \mathrm{~mL}$ ) were collected from 6 Holstein cows (milk yield 40 to $50 \mathrm{~kg} / \mathrm{d}$ ) selected at random from the University of Nottingham dairy herd. Cows were fed a TMR containing maize silage, grass silage, wheat, soy, protected fat, and a mineral/vitamin supplement. Milk lipids were separated in triplicate subsamples by method A (Hara and Radin, 1978) or method B (our simplified centrifugation method).

In method A, a 10-mL fresh-milk sample was centrifuged at $12,000 \mathrm{rpm}(17,800 \times \mathrm{g})$ for $30 \mathrm{~min}$ at $4^{\circ} \mathrm{C}$. An aliquot (350 to $400 \mathrm{mg}$ ) of the top fat-cake layer was removed and placed into a $15-\mathrm{mL}$ solvent-resistant tube, which had been rinsed with hexane. Hexane:isopropanol (3:2 vol/vol; containing $50 \mathrm{mg}$ of butylated hydroxytoluene to prevent oxidation of milk fatty acids) was added at $18 \mathrm{~mL} / \mathrm{g}$ of fat cake. After vortexing for $1 \mathrm{~min}$, a sodium sulfate solution $(6.7 \%$ in distilled water) was added at the rate of $12 \mathrm{~mL} / \mathrm{g}$ of fat cake to separate hexane from isopropanol. The tube was then vortexed for $1 \mathrm{~min}$ and allowed to stand until layer 
separation was complete (1 $\mathrm{min})$. The upper hexane layer was then transferred to a clean $15-\mathrm{mL}$ glass test tube (prerinsed with hexane) containing $1 \mathrm{~g}$ of anhydrous sodium sulfate, vortexed, flushed with nitrogen, and left to stand for $30 \mathrm{~min}$. The top layer (hexane + milk lipid) was then transferred to another tube (prerinsed with hexane) and the hexane evaporated by blowing with nitrogen on a heating block at $40^{\circ} \mathrm{C}$ for approximately $30 \mathrm{~min}$, until the weight change was less than $0.5 \mathrm{mg}$.

In method B, $20 \mathrm{~mL}$ of fresh bovine milk in a 50 $\mathrm{mL}$ conical plastic tube was centrifuged at $12,000 \mathrm{rpm}$ $(17,800 \times \mathrm{g})$ for $30 \mathrm{~min}$ at $4^{\circ} \mathrm{C}$. An aliquot $(1.0 \mathrm{~g})$ of the fat-cake layer was transferred to a $1.5-\mathrm{mL}$ microtube and left at room temperature $\left(\sim 20^{\circ} \mathrm{C}\right)$ for approximately 20 min until the fat cake melted. This was then centrifuged at $13,000 \mathrm{rpm}(19,300 \times \mathrm{g})$ for $20 \mathrm{~min}$ at room temperature by microcentrifuge (MSE Micro Centaur; Sanyo Gallenkamp, Loughborough, UK). After centrifugation, the fat had separated into 3 layers: the top layer of lipid; the middle layer of protein, fat, and other water-insoluble solids; and the bottom layer of water.

For each method, $40 \mathrm{mg}$ of separated lipid was transesterified by the method of Christie (1982), as modified by Chouinard et al. (1999). Fatty acid methyl esters were quantified using a gas chromatograph (6890; Agilent Technologies, Stockport, UK) equipped with a flame-ionization detector (7673 FID), autosampler (7683), automatic injector (7683), split injection port and a $100-\mathrm{m}$ fused silica capillary column (i.d., 0.25 $\mathrm{mm}$ ) coated with $0.2 \mu \mathrm{m}$ film of cyanopropylpolysiloxane (CP-SIL 88; Varian). Hydrogen was used as the carrier $(2.1 \mathrm{~mL} / \mathrm{min})$ and fuel gas $(32 \mathrm{~mL} / \mathrm{min})$. All gases were passed through $7-\mu \mathrm{m}$ inline filters (Nupro Co., Willoughby, $\mathrm{OH})$. Injector and detector temperatures were maintained at $225^{\circ} \mathrm{C}$. Fatty acid profiles were determined by triplicate injection of $2 \mu \mathrm{L}$, with a split ratio of $1: 100$, using a temperature gradient program based on Griinari et al. (1998). Column temperature was held at $70^{\circ} \mathrm{C}$ for 4 min postinjection, increased to $110^{\circ} \mathrm{C}\left(8^{\circ} \mathrm{C} / \mathrm{min}\right)$, increased to $170^{\circ} \mathrm{C}\left(5^{\circ} \mathrm{C} /\right.$ $\mathrm{min})$, held at $170^{\circ} \mathrm{C}$ for $10 \mathrm{~min}$, raised to $225^{\circ} \mathrm{C}\left(4^{\circ} \mathrm{C} /\right.$ $\mathrm{min})$, raised to $240^{\circ} \mathrm{C}\left(20^{\circ} \mathrm{C} / \mathrm{min}\right)$, and held for $5 \mathrm{~min}$. Postrun temperature was $190^{\circ} \mathrm{C}$. Peaks were identified using pure methyl ester standards (FIM-FAME-7 mixture; Matreya Inc., PA; and CLA standard, Sigma, Poole, UK) and peak areas for individual FA were corrected for recovery using a butter-oil reference standard (CRM 164; Commission of the European Community Bureau of References, Brussels, Belgium).

One hundred eight FA profiles were produced by replicating each separation method 3 times, and using 3 column injections per separation, for each of the
6 cows; this allowed us to compare sources of error throughout each procedure. Variance components, means, and stratum coefficients of variation were estimated using the residual maximum likelihood (REML) algorithm of Genstat 6 (Lawes Agricultural Trust, Harpenden, UK). Method was a fixed effect; cow, separation replicate, and injection replicate were random effects. The model used to describe the data, therefore, was:

$$
\mathrm{FAME}_{\mathrm{ijkl}}=m+\mathrm{M}_{\mathrm{i}}+\mathrm{C}_{\mathrm{ij}}+\mathrm{S}_{\mathrm{ijk}}+\mathrm{I}_{\mathrm{ijkl}}
$$

where $m$ is the overall constant, $\mathrm{M}_{\mathrm{i}}$ is the fixed effect of separation method $\mathrm{i}(\mathrm{i}=1,2), \mathrm{C}_{\mathrm{ij}}$ is the effect of cow $\mathrm{j}(\mathrm{j}=1 \ldots 6), \mathrm{S}_{\mathrm{ijk}}$ is the effect of separation number $\mathrm{k}$ $(\mathrm{k}=1 \ldots 3), \mathrm{I}_{\mathrm{ijkl}}$ is the effect of injection number $\mathrm{l}(\mathrm{l}=$ $1 \ldots 3)$.

\section{RESULTS AND DISCUSSION}

There was no significant difference between separation methods for any of the FA identified (Table 1). On average, $95.9 \%$ of the variation in individual FA content was due to differences between cows; only $1.4 \%$ was due to separation method, which is comparable with the variation between replicate separations $(0.7 \%)$ and between repeat injections onto the column (2.1\%). Similarly, the coefficients of variation were comparable for separation method, replicate and injection. The magnitudes of the coefficients of variation suggest that there is little to be gained by replicating separations or injections, compared with the increase in precision gained by analyzing samples from more animals.

The proportions of unidentified FA were small ( $\sim 2 \%)$ and did not differ between methods. However, the proportions of variance in the unidentified FA fraction that could be attributed to method, replication, and injection were much greater than for individual FA; this is because the unidentified fraction is determined by difference, so it contains the sum of all the slight errors in measuring individual FA.

The proposed method (method B) is useful for large numbers of milk samples (200/d), but it should be noted that the fat composition might not represent all the lipid classes present in milk. Although 97 to $98 \%$ of milk fat is composed of triglycerides contained in fat globules, which will be present in the top layer when centrifuged, some phospholipids will remain in the skim milk (Jensen, 1992). As with the conventional method (method A), the skim-milk fraction is discarded after the first centrifugation step; it is possible, however, that the second centrifugation step might lead to further losses of phospholipids in the middle 
Table 1. Mean proportions of selected fatty acids ( $\mathrm{mg} / \mathrm{g}$ of total fatty acids) identified in milk using 2 methods of lipid separation. Each method was replicated on 6 cows, using 3 separations and 3 column injections. For each source of variation, variance accounted for (\%), and coefficient of variation (\%) are shown.

\begin{tabular}{|c|c|c|c|c|c|c|c|}
\hline \multirow[b]{2}{*}{ Fatty acid $^{1}$} & \multicolumn{3}{|c|}{ Method $^{2}$} & \multicolumn{4}{|c|}{ Percentage of total variance (CV \%) } \\
\hline & $\mathrm{A}$ & B & SEM & Cow & Method & Replicate & Injection \\
\hline $\mathrm{C}_{4: 0}$ & 37.2 & 37.9 & 0.33 & $93.9(13.5)$ & $1.0(2.1)$ & $3.5(2.8)$ & $1.6(1.8)$ \\
\hline $\mathrm{C}_{6: 0}$ & 24.0 & 23.8 & 0.13 & $95.9(10.7)$ & $1.0(1.3)$ & $0.6(1.3)$ & $2.5(1.7)$ \\
\hline $\mathrm{C}_{8.0}$ & 12.0 & 12.0 & 0.09 & $97.7(14.4)$ & $1.3(1.8)$ & $0.2(1.0)$ & $0.8(1.3)$ \\
\hline $\mathrm{C}_{10: 0}$ & 22.6 & 22.8 & 0.12 & $99.2(20.8)$ & $0.4(1.3)$ & $0.0(0.9)$ & $0.4(1.4)$ \\
\hline $\mathrm{C}_{10: 1}$ & 1.8 & 1.8 & 0.01 & $99.2(27.7)$ & $0.2(1.6)$ & $0.1(1.4)$ & $0.4(1.8)$ \\
\hline $\mathrm{C}_{12: 0}$ & 22.2 & 22.5 & 0.12 & $99.3(20.4)$ & $0.3(1.3)$ & $0.0(0.8)$ & $0.4(1.2)$ \\
\hline $\mathrm{C}_{14: 0}$ & 80.5 & 81.6 & 0.38 & $98.8(15.2)$ & $0.4(1.1)$ & $0.3(1.0)$ & 0.5 \\
\hline $\mathrm{C}_{14: 1}$ & 6.3 & 6.2 & 0.03 & $99.7(34.1)$ & $0.0(1.0)$ & $0.1(1.4)$ & $0.2(1.5)$ \\
\hline $\mathrm{C}_{15.0}$ & 6.4 & 6.5 & 0.03 & $99.5(22.6)$ & $0.2(1.1)$ & $0.1(0.9)$ & $0.3(1.2)$ \\
\hline $\mathrm{C}_{15: 0}$ iso & 1.4 & 1.4 & 0.01 & $98.8(18.0)$ & $0.1(0.9)$ & $0.0(1.1)$ & $1.0(1.8)$ \\
\hline $\mathrm{C}_{15: 0}$ anteiso & 2.9 & 2.9 & 0.01 & $99.5(19.5)$ & $0.0(0.4)$ & $0.0(0.9)$ & $0.5(1.4)$ \\
\hline $\mathrm{C}_{15: 1}$ & 2.2 & 2.2 & 0.01 & $94.5 \quad(9.3)$ & $1.7(1.4)$ & $0.1(1.1)$ & $3.7(1.8)$ \\
\hline $\mathrm{C}_{16: 0}$ & 281.1 & 285.5 & 1.22 & $94.5 \quad(6.2)$ & $2.0(1.1)$ & $1.8(1.0)$ & $1.7(0.8)$ \\
\hline $\mathrm{C}_{16: 1}$ & 17.2 & 16.8 & 0.10 & $99.2(28.5)$ & $0.2(1.5)$ & $0.1(1.4)$ & $0.5(2.0)$ \\
\hline $\mathrm{C}_{17: 0}$ & 4.2 & 4.2 & 0.05 & $88.0(10.3)$ & $7.2(3.0)$ & $1.3(1.7)$ & $3.5(2.0)$ \\
\hline $\mathrm{C}_{17.1}$ & 3.9 & 4.0 & 0.02 & $96.6(10.0)$ & $0.1(1.0)$ & $1.8(1.6)$ & $1.5(1.2)$ \\
\hline $\mathrm{C}_{18: 0}$ & 97.3 & 100.7 & 0.74 & $93.5 \quad(8.8)$ & $3.2(1.8)$ & $2.4(1.5)$ & $0.9(0.9)$ \\
\hline $\mathrm{C}_{18 \cdot 1} \mathrm{c} 9$ & 276.6 & 270.6 & 1.01 & $98.4(10.9)$ & $0.4(0.9)$ & $0.7(1.0)$ & $0.5(0.8)$ \\
\hline $\mathrm{C}_{18: 1} \mathrm{c} 11$ & 12.6 & 12.6 & 0.15 & 87.7 (11.6) & $5.4(3.0)$ & $0.0(1.6)$ & $6.9(3.3)$ \\
\hline $\mathrm{C}_{18: 1} \mathrm{t} 6-8$ & 3.3 & 3.3 & 0.01 & $95.3(13.7)$ & $0.1(1.1)$ & $0.0(1.5)$ & $4.6(3.1)$ \\
\hline $\mathrm{C}_{18: 1}$ t9 & 2.9 & 2.9 & 0.03 & $94.9(12.8)$ & $2.5(2.2)$ & $0.0(0.9)$ & $2.5(2.2)$ \\
\hline $\mathrm{C}_{18: 1} \mathrm{t} 10$ & 3.7 & 3.8 & 0.06 & $93.7(17.7)$ & $4.1(3.8)$ & $0.0(1.3)$ & $2.2(2.8)$ \\
\hline $\mathrm{C}_{18: 1} \mathrm{t} 11$ & 14.5 & 14.2 & 0.15 & $95.0(17.5)$ & $1.7(2.6)$ & 0.0 & $3.2(3.4)$ \\
\hline $\mathrm{C}_{18: 1} \mathrm{t} 12$ & 5.3 & 5.3 & 0.03 & $98.0(14.0)$ & $1.0(1.5)$ & $0.0(0.8)$ & $1.0(1.4)$ \\
\hline $\mathrm{C}_{18 \cdot 1} \mathrm{t} 16$ & 4.2 & 4.2 & 0.03 & $94.1(11.1)$ & $2.2(1.9)$ & $1.5(1.7)$ & $2.3(1.7)$ \\
\hline $\mathrm{C}_{18: 2} \mathrm{c} 9, \mathrm{c} 12$ & 22.4 & 22.3 & 0.07 & $95.5 \quad(8.1)$ & $0.0(0.7)$ & $1.6(1.3)$ & $2.9(1.4)$ \\
\hline $\mathrm{C}_{18 \cdot 2} \mathrm{c} 9, \mathrm{t} 11$ & 3.8 & 3.7 & 0.02 & $96.3(16.0)$ & $0.1(1.4)$ & $0.9(2.2)$ & $2.7(2.7)$ \\
\hline $\mathrm{C}_{18: 3}$ & 4.5 & 4.5 & 0.02 & $90.4 \quad(8.7)$ & $0.0(1.1)$ & $1.4(1.9)$ & $8.1(2.6)$ \\
\hline $\mathrm{C}_{20: 0}$ & 1.5 & 1.5 & 0.01 & $92.7 \quad(9.0)$ & $2.4(1.8)$ & $2.8(1.7)$ & $2.0(1.3)$ \\
\hline \multicolumn{4}{|c|}{ Mean of identified fatty acids } & $95.9(15.2)$ & $1.4(1.6)$ & $0.7(1.3)$ & $2.1(1.8)$ \\
\hline Unidentified & 21.6 & 18.6 & 1.40 & $16.5(23.2)$ & $8.9(20.0)$ & $9.4(25.4)$ & $65.2(36.7)$ \\
\hline
\end{tabular}

\footnotetext{
${ }^{1}$ Only fatty acids at greater than $1 \mathrm{mg} / \mathrm{g}$ of total FA are reported.

${ }^{2}$ Method A uses a conventional solvent extraction method (Hara and Radin, 1978); Method B uses centrifugation to separate milk lipids before methylation. There was no significant difference between methods for any fatty acid.
}

layer, just as some of the lipid remains in the isopropanol layer of method A. This is not important for the majority of studies on milk fat, unless phospholipids need to be specifically quantified. Losses of volatile FA were similar for the 2 methods; uncorrected proportions of $\mathrm{C}_{4: 0}$ were $29.3 \mathrm{mg} / \mathrm{g}$ of total FA for method A and $30.0 \mathrm{mg} / \mathrm{g}$ of total FA for method B (SEM = 0.59), suggesting a loss of approximately $20 \%$ in each case (probably mainly in the transesterification procedure), which is corrected using the reference standard.

\section{CONCLUSIONS}

We conclude that the rapid lipid separation method produces results that are statistically indistinguishable from results produced with the Hara and Radin (1978) solvent extraction method. However, the rapid method has the following advantages: it saves more than $60 \%$ time in lipid separation; more than $90 \%$ in chemical costs; more than $70 \%$ in labor; it benefits the environment because it does not use solvents; and it is suitable for large throughput of samples.

\section{ACKNOWLEDGMENTS}

We would like to thank Jim Craigon for statistical advice. This work is part of a project on Nutritional, Hormonal, and Genetic Influences on Milk Fat Composition in Dairy Cows (LS3517) funded by the Department for Environment, Food, and Rural Affairs.

\section{REFERENCES}

Chouinard, P. Y., L. Corneau, A. Saebo, and D. E. Bauman. 1999. Milk yield and composition during abomasal infusion of conjugated linoleic acids in dairy cows. J. Dairy Sci. 82:2737-2745.

Christie, W. W. 1982. A simple procedure for rapid transmethylation of glycerolipids and cholesterol esters. J. Lipid Res. 23:10721075 . 
Griinari, J. M., D. A. Dwyer, M. A. McGuire, D. E. Bauman, D. L. Palmquist, and K. V. Nurmela. 1998. Trans-octadecenoic acids and milk fat depression in lactating dairy cows. J. Dairy Sci. $81: 1251-1261$

Hara, A., and N. S. Radin. 1978. Lipid extraction of tissues with a low-toxicity solvent. Anal. Biochem. 90:420-426.

Jensen, R. G. 1992. Fatty acids in milk and dairy products. Pages 95-135 in Fatty Acids in Foods and Their Health Implications. C. K. Chow, ed. Marcel Dekker, New York, NY.
Lock, A. L., and P. C. Garnsworthy. 2002. Independent effects of dietary linoleic and linolenic fatty acids on the conjugated linoleic acid content of cows' milk. Anim. Sci. 74:163-176.

Lock, A. L., and P. C. Garnsworthy. 2003. Seasonal variation in conjugated linoleic acid and $\Delta 9$-desaturase activity in dairy cows. Livest. Prod. Sci. 79:47-59.

Sukhija, P. S., and D. L. Palmquist. 1988. Rapid method for determination of total fatty acid content and composition of feedstuffs and feces. J. Agric. Food Chem. 36:1202-1206. 